\title{
Postpartum IUCD: its acceptance and complications
}

\author{
Nishi Garg*, Seema Grover, Bhupinder Kaur
}

Department of Obstetrics and Gynecology, GGS Medical College and Hospital, Faridkot, Punjab, India

Received: 24 April 2017

Accepted: 22 May 2017

\section{*Correspondence:}

Dr. Nishi Garg,

E-mail: nishigargdr@yahoo.co.in

Copyright: (C) the author(s), publisher and licensee Medip Academy. This is an open-access article distributed under the terms of the Creative Commons Attribution Non-Commercial License, which permits unrestricted non-commercial use, distribution, and reproduction in any medium, provided the original work is properly cited.

\begin{abstract}
Background: Intra Uterine Contraceptive Device is the most commonly used reversible method of contraception worldwide. Immediate PPIUCD insertion is labelled when intra uterine device is inserted within 10 minutes to 48 hours of expulsion of placenta. The objective of the study was to determine the proportion of women accepting PPIUCD, factors influencing its acceptance, to look for side effects like bleeding disturbances, expulsion, lost strings, pain abdomen and pelvic infection etc. and the drop-out rates for follow up after PPIUCD.

Methods: This was an open prospective, and longitudinal study to assess the safety and acceptance of the Multi-load when inserted within 10 minutes to 48 hours of placental expulsion.

Results: During the period of January 2015 to November 2015 there were total 1624 deliveries in the said period in the department of Obstetrics and gynaecology of GGS Medical College and Hospital Faridkot. Out of these 714 delivered by LSCS and 910 delivered Vaginally. After excluding 470 patients were counselled, only $97(20.64 \%)$ accepted PPIUCD. Out of these $67(69 \%)$ patients had post placental insertion. 15.4\% underwent immediate postpartum insertion. $15.4 \%$ got PPIUCD with cesarean section. (25.77\%) patients had missing threads/strings, 12 $(12.37 \%)$ patients had mild pain and 9 women $(9.27 \%)$ had excessive discharge.

Conclusions: PPIUCD is cost effective and a very safe means of contraception. Postpartum period is the period when patient is highly motivated for contraception and can be easily counselled. PPIUCD has a huge potentiality and abundant scope in India and if widely used it will have a strong impact on population control and will prevent unplanned pregnancy and its sequelae.
\end{abstract}

Keywords: Acceptance, PPIUCD, Postpartum, Women

\section{INTRODUCTION}

During post-partum period both new born and the mother need special care. At this time, the women would prefer to avoid pregnancy and are highly motivated to use contraceptive measures. Intra Uterine Contraceptive Device is the most commonly used reversible method of contraception worldwide with about 127 million current users. $^{1}$ This contraceptive protection with TCu380A is similar to that achieved by tubal sterilisation with an added advantage of reversibility. Further, compared to tubectomy, IUCD is less expensive and simpler. ${ }^{2}$ Immediate PPIUCD insertion is labelled when intra uterine device is inserted within 10 minutes to 48 hours of expulsion of placenta. Moreover, there are studies showing PPIUCD as an ideal contraceptive method advised during this period as there is no interference with breastfeeding and allows women to obtain safe, long acting, highly effective contraception while already under medical specialist observation. ${ }^{3}$ Further recommencement of ovulation is usually unpredictable after delivery. This can be managed very effectively by $\mathrm{CuT}$ as a contraceptive during puerperium. ${ }^{4}$ Further, in developing countries like India, delivery might be the only time when a healthy woman is in contact with the health care provider and her chances of returning for contraceptive 
advice are uncertain. Moreover, there are studies that show that in India, $65 \%$ of women have an unmet need for family planning in the first five post-partum. ${ }^{3}$ In another study, it was shown that IUCD insertion rate was as high as $95 \%$ in patients willing for immediate postpartum insertion, whereas this rate decreased to only $45 \%$ in those consenting for a later insertion. ${ }^{5}$ Thus family planning measures should include ante partum counselling and immediate PPIUCD insertion for those who are willing.

This might help in curtailing the fertility rates. However, PPIUCD insertion may increase the risk of adverse events such as perforation, pain, bleeding as well as very high chances of spontaneous expulsion. ${ }^{3,6}$ Recent studies have indicated a significant decrease in expulsion rate after insertion of IUCD with a proper technique used by a trained provider. ${ }^{7}$ The current national strategy in India is to increase the use of IUCD as contraceptive measure. The available target for PPIUCD as a method of contraceptive has also increased with the 10-fold increase in women delivering in hospitals due to maternity benefit scheme. ${ }^{3}$ There are very few studies regarding the efficacy, safety and expulsion rates of TCu380A, a recently marketed IUCD after it insertion in immediate post-partum period.

With this background, the present study was done to assess the acceptance and to look for safety, expulsion rates and side effects of IUCD inserted immediate after the delivery within 10 minutes to 48 hours of delivery. The acceptability of this device and the ease of insertion by trained personnel and the dropout rate for follow up were also assessed.

The objective of the study was to determine the proportion of women accepting PPIUCD. To see factors influencing its acceptance. To determine the symptoms like bleeding disturbances, expulsion, lost strings, pain abdomen and pelvic infection etc. To see the drop-out rates for follow up after PPIUCD.

\section{METHODS}

This was an open prospective, and longitudinal study to assess the safety and acceptance of the Multiload when inserted within 10 minutes to 48 hours of placental expulsion. Study participants were recruited through hospital antenatal clinics. Postpartum contraception was routinely discussed at prenatal visits.

All antenatal patients who came for delivery in labor room irrespective of maternal age, risk factors and proposed mode of delivery at, Guru Gobind Sing Medical Hospital, Faridkot, Punjab, India were counselled at their visits after 34 weeks of gestation on contraceptive options.

Those willing for immediate postpartum insertion of Multiload IUCD within 10 minutes to 48 hours of placental expulsion were included in the study group and informed consent was obtained. Those opting for insertion at 6 weeks/or permanent method of sterilization or other temporary methods were offered the same.

\section{Inclusion criteria}

All antenatal patients admitted at the center at around 36 to 40 weeks of gestation at our institution whose consent was obtained prior to admission were included following the following inclusion criteria:

- $\quad 18$ - 40 years old

- 34 - 40 weeks Gestational Age

- Anticipate vaginal delivery/C section

- No prior cesarean delivery

- No infections.

- $\mathrm{Hb} \geq 8 \mathrm{~g} / \mathrm{dl}$

- No Diabetes Mellitus, Hypertension

- Giving informed consent to have CuT after counseling.

\section{Exclusion criteria}

These patents were be excluded out of the study.

- Less than 8 gm\% Haemoglobin.

- With pelvic infection or sepsis

- Temperature $>38^{\circ} \mathrm{C}$ during or after labor.

- $\mathrm{PPH}$.

- Fibroid.

- $\quad$ Ruptured membranes $>18$ hrs

- obstructed Labor.

- Jaundice.

- Congenital Malformation.

- Extensive genital trauma.

- Not giving informed consent.

After following the inclusion and exclusion criteria, those patients who were found eligible to participate in the study were given insertion of IUCD after 10 minutes to 48 hours of delivery of placenta.

\section{Types of insertion}

- Postplacental: Postplacental insertion of the IUCD was done immediately following delivery of the placenta, typically within 10 minutes. Postplacental insertion was done by two techniques:

- Intra cesarean: the IUCD was introduced through the uterine incision during a caesarean section and placed at the uterine fundus. This is done manually or using a regular ring forceps, since it is not necessary to use a long instrument to reach the fundus. After the placenta is removed, the provider inserted the IUCD, and then closed the uterine incision.

- Immediate postpartum: the IUCD was inserted within 48 hours following the birth of the baby. 


\section{Follow up}

Follow up schedule was done at 6 weeks after insertion and the following things were assessed:

- Whether patient came in at the six-week schedule.

- If patient presents for earlier follow up because of pain/bleeding/fear/foul discharge/ demanding removal.

- Willingness to continue the $\mathrm{Cu}$ IUCD as a method of contraception.

- The patients wanting removal of $\mathrm{Cu} \mathrm{T}$ will be considered as discontinuations.

- Expulsion rates at 6 weeks follow-up were measured.

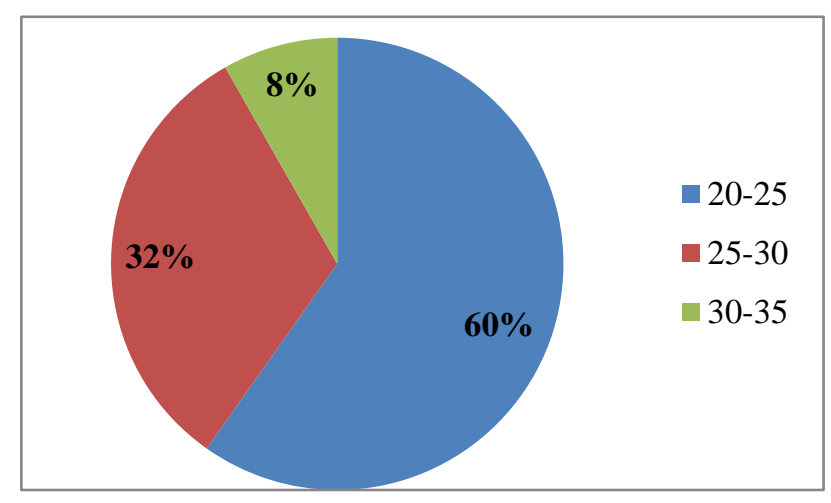

Figure 1: Age distribution of patients.

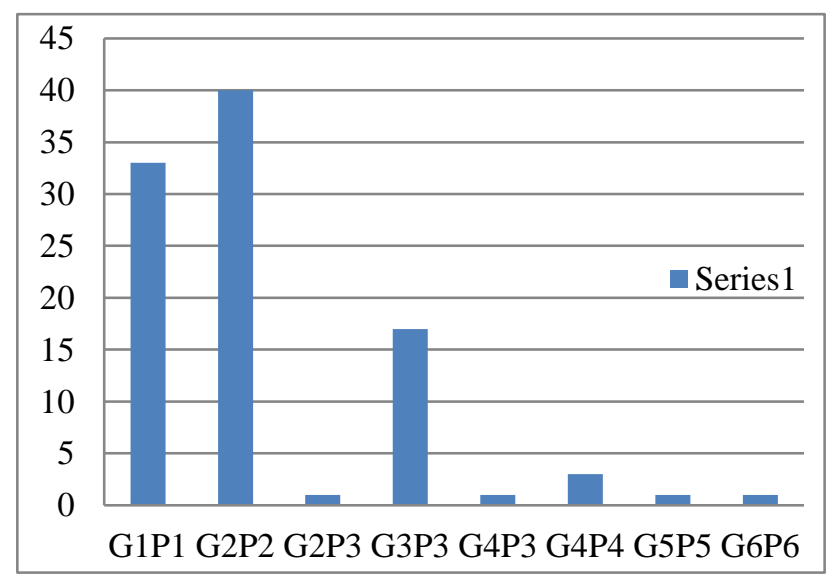

Figure 2: Distribution of gravidity and parity.

\section{RESULTS}

During the period of January 2015 to November 2015 there were total 1624 deliveries in the said period in the department of Obstetrics and gynaecology of GGS Medical College and Hospital Faridkot. Out of these 714 delivered by LSCS and 910 delivered Vaginally. After excluding 470 patients were counselled, only 97 (20.64\%) accepted PPIUCD. Out of these 67 (69\%) patients had post placental insertion. $15.4 \%$ underwent immediate postpartum insertion. $15.4 \%$ got PPIUCD with cesarean section. $61.85 \%$ patients were in the age group of 20 to 25 years and $32.88 \%$ were in the age group of 25 to 30 years. Out of all patients $68.04 \%$ were unbooked and came through emergency. $41.2 \%$ women were 2 nd gravidae and $34 \%$ were primigravidae. $71.13 \%$ were from Rural background and $31.96 \%$ were from urban background. 22 Patients $(22.68 \%)$ lost follow up whereas $52(53.60 \%)$ came for follow up at 4 to $6 \mathrm{wks}$. $23.71 \%$ patients were called telephonically and with the help of Staff nurse and Asha worker of that area, follow up was done. At the time of follow up the various complaints were asked and noted down. 25 (25.77\%)patients had missing threads/strings. In 17 cases, strings were found in cervical canal. Eight cases needed ultrasound and confirmed that the IUCD was in situ. 12 (12.37\%) patients had mild pain Most of them were treated with analgesics but 4 got it removed because of pain. 9 women $(9.27 \%)$ had excessive discharge. Treatment given and majority got well with time but 2 patients got it removed. 11 women (11.34\%) had menorrhagia Most of them were treated with Tranaxemic acid but still 2 patients got it removed. In $9.27 \%$ Patients IUCD was expelled. With Ultrasound and X-ray it was confirmed as expulsion. In our study, there were not much serious side effects, no case of perforation or displaced IUCD was there in our study.

\section{DISCUSSION}

Women are highly motivated in postpartum period to initiate contraception. ${ }^{6,8}$ At this time they come in contact with the health provider/gynaecologist and can be easily counselled. Timing of insertion, counselling and provider training are important factors for IUCD insertion in the postpartum period as quoted in United Nations Population Information Network (UN-POPIN). ${ }^{9}$ Timing of insertion is important as it influences the risk of expulsion. Ideally PPIUCD should be done in $10 \mathrm{~min}$. to $48 \mathrm{hrs}$ post placental expusion. In our study, 470 patients were counselled and only 97 women gave consent for the insertion. There were various reasons for less acceptance. Fear of perforation and resistance from other family members were the common reasons for less acceptance. The other reasons were fear of excessive bleeding, pain and willingness to go for permanent methods of contraception. The continuation rate of PPIUCD was $57.73 \%$. Few $(10.3 \%)$ got it removed because of side effects and in $9.2 \%$ it got expelled spontaneously. We lost follow up in $22.68 \%$ of patients. On comparison with other studies, acceptance was low as was there in other studies. No major complications were seen in any of the studies which are done previously by various authors. Menorrhagia which is the common complaint with IUCD, was seen least in our study i.e. $11.34 \%$. It was $27.23 \%$ in Shukla M et al where they inserted CuT 200 B. ${ }^{10}$ Also study by Sujnanendra M et al where they used CuT 380A and found menorrhagia to be $25.5 \% .^{11}$ Nearly $21 \%$ women had excessive and irreular bleeding in a study done by Verma A et al. ${ }^{12}$ Menorrhagia was $13.04 \%$ seen in Singhal Sunita et al after one month of follow up. ${ }^{13}$ With the use of Multiload, the complaint of menorrhagia 
was less $(11.3 \%)$ in a study done by Welcovic et al where they studied postpartum bleeding and infection after postplacental IUCD insertion and found no difference in the incidence of excessive bleeding. ${ }^{14}$ Loss of follow up was also a common feature in all the studies.it was $58 \%$ in a study done by Nayak et al, $40 \%$ by Verma Anita et al and it was $22.68 \%$ in our study. ${ }^{15,12}$

Table 1: Comparison of side effects with various studies.

\begin{tabular}{|l|l|l|}
\hline Type of IUCD & $\begin{array}{l}\text { Other studies } \\
\text { Cu T 380 A } \\
\text { 200- B }\end{array}$ & Multiload 375 \\
\hline Acceptance & Low & low \\
\hline Menorrhagia & $\begin{array}{l}\text { 13 to 27\% } \\
\text { approx }\end{array}$ & Less 11.3\% \\
\hline Missing Srtings & 10 to 36 \% & $25.77 \%$ \\
\hline $\begin{array}{l}\text { Lower Abdominal } \\
\text { Pain }\end{array}$ & None to 13.3\% & $12.6 \%$ \\
\hline infection & None to $11.2 \%$ & none \\
\hline Expulsion & $2.5 \%$ to $10.68 \%$ & $9.27 \%$ \\
\hline Lost follow up & 21 to $58 \%$ & $20.6 \%$ \\
\hline
\end{tabular}

In a study done by Kittur et al, they had $80 \%$ patients reported for follow up at 6 weeks. ${ }^{7}$ The lower levels of education, low socio-economic status and less means of transport might be responsible for patients not able to reach for follow up. We had contact numbers and good contact with asha workers and ANMs, so we were able to take follow up from them in few patients. The complaints of pain abdomen, missing strings was almost same as in previous studies. Missing threads were seen in $19.8 \%$ in Verma A etal, $11.2 \%$ by Shukla et al whereas these were $25.77 \%$ in present study.

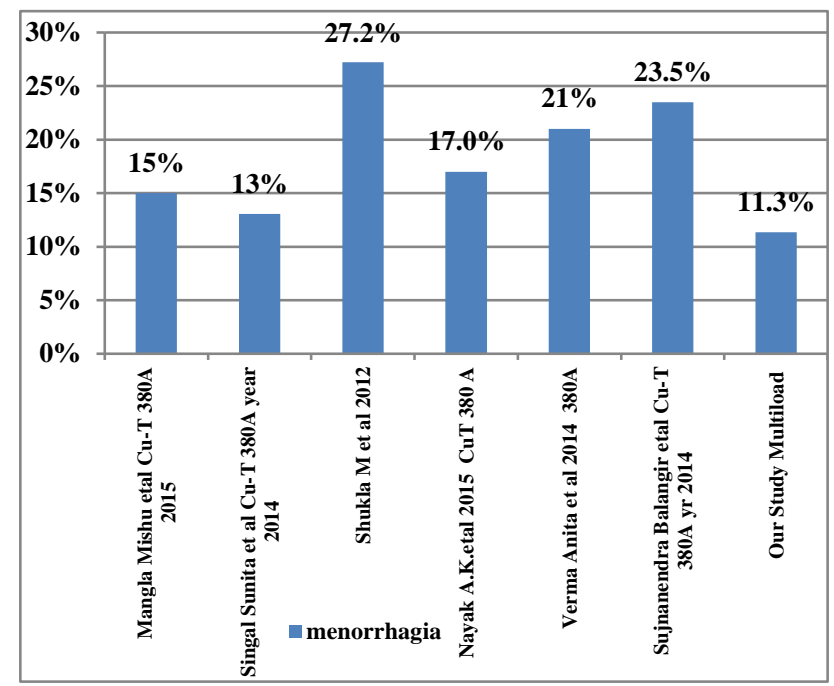

Figure 3: Distribution of side effects.

In 17 patients, they were lying in cervical canal, were pulled and cut short. Shukla etal reported cumulative expulsion rate to be $10.68 \%$, Afsan et al have reported it to be $6 \%$, Katheit $\mathrm{G}$ et al reported it to be $10.5 \%$ and it was $9.27 \%$ in our study. ${ }^{16,17}$ Kapp et al had done systemic review of 15 articles on PPIUCD, they did not find any increase in risk of complications. ${ }^{18}$ Awareness of the PPIUCD among these women was very poor.

Majority of the women never heard about the PPIUCD before admission to labor room. The acceptance of PPIUCD was not very high in the present study, as is also reported in other studies globally. The increased institutional deliveries are the opportunity to provide women easy access to immediate PPIUCD services.

Shahnazi M et al did a Double-blind clinical trial to Compare side effects of Copper T380A and Multiload $375 .{ }^{19}$ The results of this study showed that the use of the IUD ML CU 375 causes a significant decrease in the rate of bleeding, as well as severity and duration of dysmenorrhea.

Limitation of our study was small sample size therefore, results may not be applicable to all women undergoing IUCD insertion. No Antenatal Counselling. Very brief counselling just before delivery and cesarean section. Thus, more qualitative and quantitative research is needed to be done in order to analyse the side effects and acceptance of PPIUCD.

\section{CONCLUSION}

PPIUCD is cost effective and a very safe means of contraception. Postpartum period is the period when patient is highly motivated for contraception and can be easily counselled. PPIUCD has a huge potentiality and abundant scope in India and if widely used it will have a strong impact on population control and will prevent unplanned pregnancy and its sequelae. The expulsion rate can be reduced with practice. The government needs to develop strategies to increase public awareness of the PPIUCD through different media sources. It is also important to arrange for more trainings on PPIUCD in order to increase knowledge and skills among healthcare providers and aid in reduction of the expulsion rates. It may be an alternative to sterilization for many couples. Cash incentives to the accepter, motivator and of course provider would bring about a substantial progress in the PPIUCD use in developing countries like India. Thus, PPIUCD can bring a revolutionary Change in the contraceptive use in the country as it is a safe, cost effective and an easily reversible method.

\section{ACKNOWLEDGMENTS}

Authors would like to thank the patients, hospital staff Nurses and Asha workers and ANM's of the area for their participation in this study. Also, special thanks to Mr. Baltej for helping in analyzing the data.

\section{Funding: No funding sources \\ Conflict of interest: None declared \\ Ethical approval: None declared}




\section{REFERENCES}

1. Nelson A. Gynaecology and Obstetrics. In: 2. Intrauterine contraceptives, Philadelphia: Lippincott Williams and Wilkins; 2004:6.

2. Peterson HB, Xia Z, Hughes JM, Wilcox LS, Tylor LR, Trussell J. The risk of pregnancy after tubal sterilization: findings from the U.S. Collaborative Review of Sterilization. Am J Obstet Gynecol. 1996;174(4):1161-8.

3. Post-partum IUCD reference manual. New Delhi: Family Planning Division, Ministry of Health and Family Welfare, Government of India; 2010.

4. Grimes DA, Lopez LM, Schulz KF, van Vliet HA, Stanwood NL. Immediate post-partum insertion of intrauterine devices. Cochrane Database Syst Rev. 2010;(5):CD003036.

5. Echeverry G. Family planning in the immediate postpartum period. Studies Fam Planning. 1973;4(2):33-5.

6. Kopp N, Curtis KM. Intrauterine device Insertion during the postpartum period A systemic review. Contraception 2009;80:327-36.

7. Kittur S, Kabadi YM. Enhancing contraceptive usage by post-placental intrauterine contraceptive devices (PPIUCD) insertion with evaluation of safety, efficacy, and expulsion. Int $\mathbf{J}$ Reprod Contracept Obstet Gynecol. 2012;1(1):26-32.

8. Celen, Moroy, Suvak, Aktulay, Danisman. Clinical outcomes of early postplacental insertion of intrauterine contraceptive devices. Contraception. 2004,69:279-82.

9. United Nations Population Information Network (POPIN) UN Population division, Department of Economic and Social Affairs with support from UN Population Fund. Network Intrauterine devices. Family Health International. Winter. 1996;16:2.

10. Shukla M, Qureshi S. Post Placental Intrauterine device insertion-A five-year experience at a tertiary care centre in North India, Int $\mathbf{J}$ Med Res. 2012; $136: 432-5$.
11. Sujanendra M. Evaluation of safety, efficacy and expulsion of postplacental and intracesarean insertion of intrauterine contraceptive devices (PPIUCD). JOGI. 2014;64:5.

12. Verma A, Sinha AR; Study of Postpartum IUCD Insertions in Tertiary Health care Centre in Bihar: Indian J Perinatol Reproduct Biol. 2014;4:8-10.

13. Singhal S, Bharti R, Dewan R, Dabral A, Batra A. Sharma M, et al. Clinical outcome of Postplacental Copper 380 a insertion in women delivering by cesarean section. JCDR. 2014;8(9):1-4.

14. Welkovic S, Costa L, Faundes A, Ximenes R, Costa C. Postpartum bleeding and infection after postplacental IUD Insertion. Contraception. 2001;63:155-8.

15. Nayak AK, Hota T. Hospital based-study regarding acceptance of PPIUCD as postpartum family planning method and its complications in a tertiary care hospital. Indian J Perinatol Reprod Biol. 2015;5(1):22-5.

16. Anjum A, Shamin AS. Immediate Postpartum IUCD (PPIUCD) Insertion: An Opportunity Not to be Missed ASH and KMDC. 2014;19(1):15-20

17. Katheit G, Agarwal J, Evaluation of Postplacental intrauterine device in terms of awareness acceptance and expulsion in tertiary care centre. Int $\mathbf{J}$ Reprod Contracept Obstet Gynecol. 2013:2(4):539-43.

18. Kappa A, Curtis KM. Intrauterine device insertion during the postpartum period: a systematic review. Contraception. 2009;80:327-36.

19. Shahnazi M, Sarrafi S, Jafarabadi MA, Azari S. Comparing Hemorrhages and Dysmenorrhea with Copper T380A and Multiload 375 Intrauterine Devices: A Randomized Clinical Trial: J Caring Sci. 2014;191-204.

Cite this article as: Garg N, Grover S, Kaur B.

Postpartum IUCD: its acceptance and complications. Int J Reprod Contracept Obstet Gynecol 2017;6:2973-7. 